\title{
On the Path of Academic Accreditation: An Outline of a Two-Phase Plan
}

\author{
Mohammed Ali Shallal \\ Scientific Research and Development Centre, Nawroz University, Duhok, Kurdistan Region - F.R. Iraq
}

\begin{abstract}
This paper presents an outline of a two-phase plan that may be pursued at Nawroz University (NZU) 'on the path of academic accreditation'. The foundation for the plan is a first phase involving raising awareness and gradually implementing institutional effectiveness (IE) enhancement activities. The activities include the initiation of an outcome based education (OBE) approach in a number of undergraduate programs, culminating at the preparation of program self-assessment reports (SARs) to be submitted for internal and external reviews. A logframe involving the main purposes of the proposed first phase is presented. Based on the progress made during the first phase, a tentative second phase plan is presented to be considered further for processes towards academic accreditation at program and/or institution level(s) in the year(s) that follow.
\end{abstract}

KEYWORDS: Nawroz University, institutional effectiveness, outcome based education, Academic accreditation, two-phase plan.

\section{INTRODUCTION}

It is generally acknowledged that higher education in some universities in the area faces a number of challenges in issues related to quality assurance (QA) and academic accreditation. Some of these challenges relate to the mode of education and curricula, faculty capacities, assessment, quality of research, and slow academic accreditation progress. ${ }^{[10-13]}$ It is felt that unless adequate efforts are put into action to face and deal with these challenges, then the existing gap is likely to widen.

The work presented represents an attempt to pave the way for tackling some of the challenges at NZU. It aims at drawing a short-term (first phase) plan over the period 2017-2020, culminating at the preparation of SARs, for some academic undergraduate programs, suitable for external reviewing and possibly followed by review group (RG) site visits.

Although the plan seems to be focusing on program effectiveness issues, it is appreciated that many more aspects covering other IE activities and establishment

Academic Journal of Nawroz University (AJNU)

Volume 6, No 3(2017), 7 pages

Received 1 May 2017; Accepted 1 August 2017

Regular research paper: Published 16 August 2017

Corresponding author's e-mail: mashallal@hotmail.com

Copyright (C2017 Mohammed Ali Shallal

This is an open access article distributed under the Creative

Commons Attribution License. of institutional arrangements to support the process need also to be addressed.

Based on the mission and objectives of a higher education institution (HEI), and in light of the progress made during the first phase, a second phase involving preparation for academic accreditation processes at program and/or institution level(s), during the year(s) that follow, may then be considered. The requirements will have to be consistent with academic accreditation criteria and standards.

In the absence of local national accreditation standards, an HEI may proceed in light of some suitable such standards from sources elsewhere at institution and/or program level(s).

The plan proposed here draws upon a number of relevant sources, which include:

i. accreditation standards, National/Programmatic. ${ }^{[7-9]}$

ii. recent reports. [10-13]

iii. current curricula and study plans of a number of accredited programs and institutions. ${ }^{[1-6]}$

iv. international guidelines: reports in the Computing Curricula Series.[14][15]

A glossary of some terms used in the paper is shown in the appendix.

\section{Overall Aims and Logframe of the First Phase:}

\subsection{Phase I Main Purposes/Aims}


- Enhancement of IE activities.

- Initiation of an OBE approach in selected programs.

- Curriculum revisions based on guidelines and accreditation standards.
- Preparation of academic program SARs for external reviews.

\subsection{Phase I Logframe:}

An outline of first phase plan 'logframe' involving the main purposes is shown below:

Table 1: First Phase Plan 'logframe'

\begin{tabular}{|c|c|c|c|c|}
\hline Purposes/Aims & Targets & Indicators & $\begin{array}{c}\text { Means of } \\
\text { Verification }\end{array}$ & Assumptions \\
\hline $\begin{array}{l}>\text { Towards an IE } \\
\text { culture }\end{array}$ & $\begin{array}{l}\text { - Enhancement of } \\
\text { QA activities } \\
\text { - Faculty/staff } \\
\text { capacity building }\end{array}$ & $\begin{array}{l}\text { - IE-related seminars } \\
\text { \& workshops } \\
\text { - Activation of } \\
\text { faculty development } \\
\text { centre } \\
\text { - Improvements } \\
\text { performed }\end{array}$ & $\begin{array}{l}\text { - Faculty \& student } \\
\text { participation } \\
\text { - Regular } \\
\text { program/unit } \\
\text { assessment reports } \\
\text { - Documents } \\
\text { prepared }\end{array}$ & $\begin{array}{l}\text { - Support \& interest } \\
\text { - Available reqd skills } \\
\text { - Faculty stability } \\
\text { - Unplanned holidays } \\
\text { dealt with }\end{array}$ \\
\hline $\begin{array}{l}\text { Initiation of an } \\
\text { OBE approach in } \\
\text { selected programs }\end{array}$ & $\begin{array}{l}\text { - Faculty/student } \\
\text { involvement } \\
\text { - Alignment aspects } \\
\text { - Improvements in } \\
\text { T\&L* processes }\end{array}$ & $\begin{array}{l}\text { - Faculty/student } \\
\text { surveys } \\
\text { - Actual course } \\
\text { plans / files } \\
\text { - Accountability/ } \\
\text { incentives/ } \\
\text { innovations }\end{array}$ & $\begin{array}{l}\text { - Course/program } \\
\text { assessments } \\
\text { - Faculty/student } \\
\text { f/b* } \\
\text { - Peer reviews }\end{array}$ & $\begin{array}{l}\text { - Faculty/students } \\
\text { collaboration } \\
\text { - Faculty ownership of } \\
\text { the processes }\end{array}$ \\
\hline $\begin{array}{l}\text { Curriculum } \\
\text { revisions based } \\
\text { on guidelines \& } \\
\text { accreditation } \\
\text { standards }\end{array}$ & $\begin{array}{l}\text { - Review } \\
\text { accreditation } \\
\text { standards } \\
\text { - Revise curricula }\end{array}$ & $\begin{array}{l}\text { - Documented } \\
\text { revised curricula \& } \\
\text { study plans }\end{array}$ & $\begin{array}{l}\text { - } \mathrm{CCs}^{*} \text { involvement } \\
\text { - Implementation } \\
\text { of revised curricula }\end{array}$ & $\begin{array}{l}\text { - Management/faculty } \\
\text { collaboration }\end{array}$ \\
\hline $\begin{array}{l}\text { Preparation of } \\
\text { program SARs for } \\
\text { external reviews }\end{array}$ & $\begin{array}{l}\text { - Preparation of } \\
\text { SARs as planned }\end{array}$ & - RG reviews/visits & $\begin{array}{l}\text { - SAR review } \\
\text { reports } \\
\text { - RG reports }\end{array}$ & $\begin{array}{l}\text { - Tasks \& timelines } \\
\text { adhered to }\end{array}$ \\
\hline
\end{tabular}

* CC: Curriculum Committee, f/b: Feedback, T\&L: Teaching \& Learning

Each of the 'Purposes' shown in the first column warrants a detailed logframe of its own.

These logframes are better built with a team effort approach and stakeholder participation.

\section{First Phase Workplans/Timelines 2017-2020 (calendar years):}

Proposed priorities and workplans/timelines for processes to be performed are presented in tables (a) \& (b) below.

(These workplans are subject to change and/or modification during the implementation processes and in light of the progress made.)

\subsection{7/2018 (calendar years) Priorities and Activities:}

1. Institution's vision, mission, goals and objectives.
2. Raise awareness/seminars/workshops.

3. Enhance IE activities.

4. Introduce an OBE approach into selected program(s). Revise curricula.

5. Strengths, Weaknesses, Opportunities and Threats (SWOT ) analysis / strategic plan / establish key performance indicators (KPIs).

6. Prepare SARs of the programs involved for internal reviews. 
Table (a) Workplan/Timeline 2017/2018 (Q: Quarter)

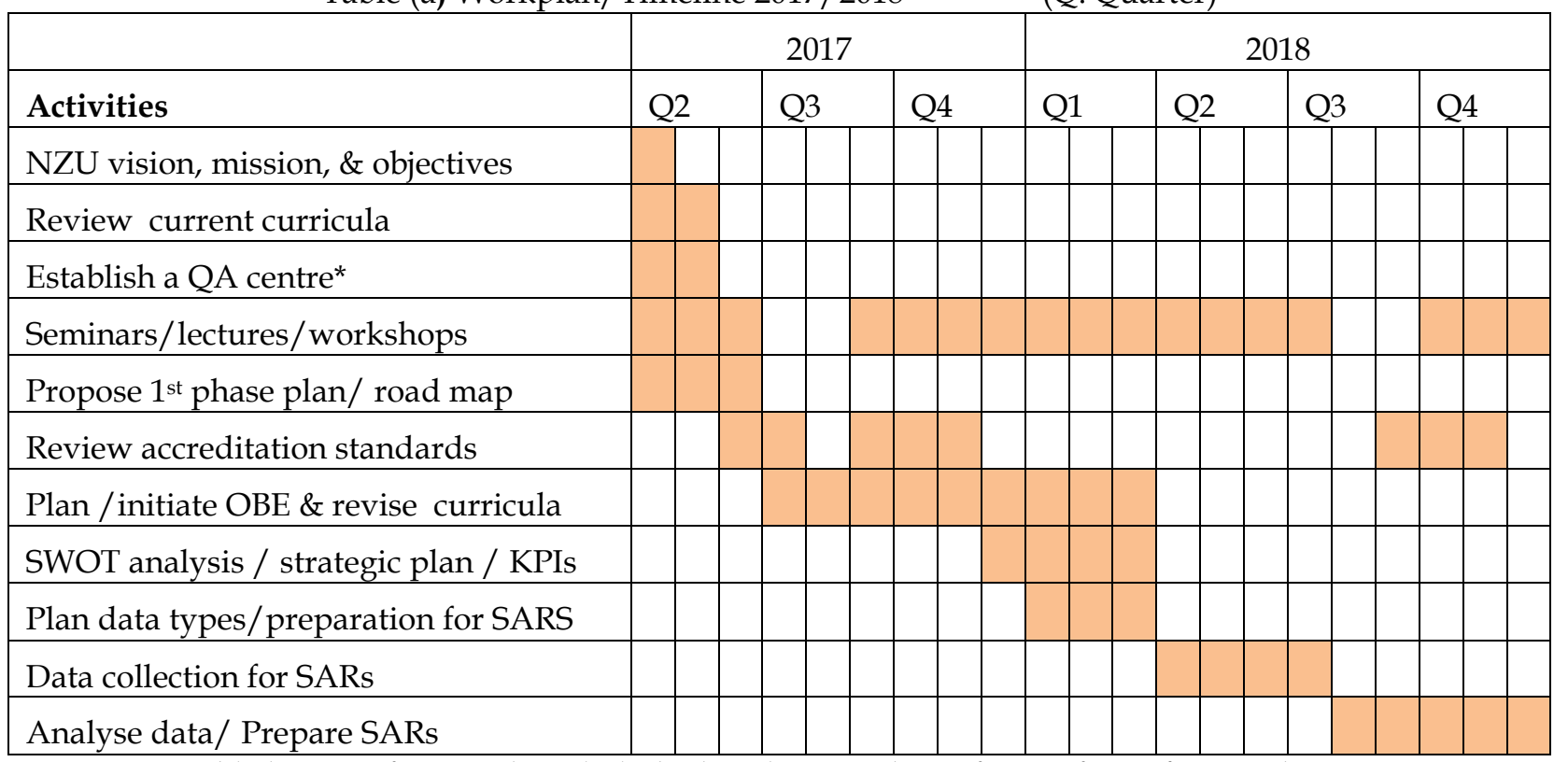

*Requirement: Establishment of a unit directly linked to the President of NZU for IE/QA and assessment purposes to help in the processes involved. (e.g., Centre of Assessment and Quality Assurance ( CAQA))

\subsection{9/2020 (calendar years) Priorities and Activities:}

1. Perform internal reviews of SARs of the programs involved.

2. Develop preliminary improvement plans and evaluate the progress in the OBE process.

3. Prepare suitable SARs of the programs involved for external reviews.
4. Revise processes \& consider inclusion of more programs in the OBE approach.

5. Enhance IE activities / KPIs.

6. Evaluate the progress made and the extent of being prepared to start accreditation processes in light of national standards at Ministry of Higher Education \& Scientific Research (MOHE) level and/or otherwise.

Table (b) Workplan/Timeline 2019/2020

\begin{tabular}{|c|c|c|c|c|c|c|c|c|}
\hline \multirow[b]{2}{*}{ Activities } & \multicolumn{4}{|c|}{2019} & \multicolumn{4}{|c|}{2020} \\
\hline & Q1 & Q2 & Q3 & Q4 & Q1 & Q2 & Q3 & Q4 \\
\hline Internal SAR revie & & & & & & & & \\
\hline Study review repor & & & & & & & & \\
\hline Improve / Revise $\mathrm{p}$ & & & & & & & & \\
\hline Review accrdn stno & & & & & & & & \\
\hline Prepare Data for SA & & & & & & & & \\
\hline Analyse data for $\mathrm{S}$ & & & & & & & & \\
\hline SARs for external $\mathrm{R}$ & & & & & & & & \\
\hline Seminars/worksho & & & & & & & & \\
\hline Institutional docs* & & & & & & & & \\
\hline
\end{tabular}

${ }^{*}$ Required Institutional Documents:

- IE/QA Manual

- Faculty Handbook

- Staff Handbook
- Student Handbook

- Academic Catalog

- Policies \& Procedures Manual 


\section{Second Phase:}

- Possible activities may be as shown in table (c):

- Details to be worked out based on the progress made.

Table (c) Tentative Workplan/Timeline 2021/2022

\begin{tabular}{|l|l|l|l|l|l|l|l|l|}
\hline & \multicolumn{2}{|l|}{2021} & \multicolumn{2}{l|}{2022} \\
\hline & Q1 & Q2 & Q3 & Q4 & Q1 & Q2 & Q3 & Q4 \\
\hline Activities & & & & & & & & \\
\hline SARs for external reviews & & & & & & & & \\
\hline External reviews of SARs & & & & & & & & \\
\hline Analyse review reports & & & & & & & & \\
\hline Perform improvements & & & & & & & & \\
\hline Consider accreditation plan & & & & & & & & \\
\hline Plan for accreditation & & & & & & & & \\
\hline
\end{tabular}

\section{A Road Map}

A Deming Wheel (illustrated below) ${ }^{[16]}$ approach is implied in the road map presented below, showing a summary of the main activities.

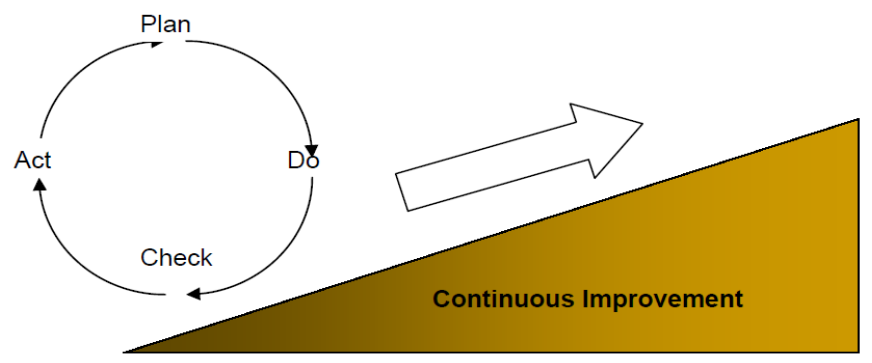

Fig 1: Deming Wheel

Table 2: Road Map

\begin{tabular}{|c|c|c|}
\hline \multicolumn{3}{|c|}{ Road Map Summary of Main Activities } \\
\hline Calendar Yr(s) & Activity & \\
\hline 2017 & $\begin{array}{l}\text { - Review current programs/Review accredit } \\
\text { - Draft/initiate OBE plan } \\
\text { - Revise curricula } \\
\text { - SWOT analysis }\end{array}$ & $\begin{array}{l}\text { ion requirements } \\
\text { PLAN } \\
\end{array}$ \\
\hline 2018 & $\begin{array}{l}\text { - Strategic plan } \\
\text { - Implement draft OBE plan } \\
\text { - Prepare SARs for internal reviews }\end{array}$ & $\underline{D O}$ \\
\hline 2019 & $\begin{array}{l}\text { - Evaluate program SARs: Internal } \\
\text { - Perform improvements and revise plans }\end{array}$ & $\frac{\underline{C H E C K}}{\underline{A C T}}$ \\
\hline 2020 & - Prepare program SARs for external reviews & $\underline{D O}$ \\
\hline 2021 & $\begin{array}{l}\text { - Perform external reviews of SARs } \\
\text { - Evaluate reviews/revise/improvements } \\
\text { - Consider plans for accreditation }\end{array}$ & $\begin{array}{l}\frac{\underline{A C T}}{C H E C K A C T} \\
\underline{D O} \underline{\mathrm{CHECK}} \underline{A C T}\end{array}$ \\
\hline
\end{tabular}




\section{Monitoring, Reporting and Evaluation}

\subsection{Monitoring}

The plan processes involved should be monitored at regular intervals through logframe indicators and outcomes of various activities in accordance with the workplan schedules given in tables (a) and (b). The Centre of Assessment \& QA is expected to have an active role in these processes. Some adjustments in the workplans and logframes themselves will be anticipated within the life of the three-year first phase plan.

\subsection{Reporting and Evaluation}

Annual reports on the progress made are to be prepared for internal purposes, as well as for submittal to the MOHE. Various internal and external assessments at course, program and supporting service levels will also contribute to the improvements of various processes.

\section{Conclusions:}

- The presented plan is part of the institutional research and QA activities at the University.

- One of the main purposes of the plan is the assessment, and subsequent improvements, of academic programs at NZU. Regular program assessment is one of the essential components of the IE process.

- Internal \& external program assessments and reviews may be performed as good-practice measures for IE/QA purposes as well as for internal improvement. Such efforts will also be valuable when the time comes for accreditation to be considered.

- Program evaluation and IE efforts need to be supported at all levels by creating a 'culture of assessment' throughout the institution.

- It is realized that starting on the path of academic accreditation does not imply that the target is in sight: hard work, over a period of time, is required.

- The establishment of a commission/agency for academic accreditation at MOHE level is recommended.

\section{Acknowledgements}

I am grateful to NZU for providing the opportunity to perform this work. Many thanks to Dr Amad AlSofi, President of NZU, Dr Haithem Al-Yousif, Vice President for Scientific Affairs, members of the
University Council and NZU faculty for the support, discussions and opinions expressed.

\section{REFERENCES}

[1] Al Ain $U$ of Science \& Technology http://www.aau.ac.ae

[2] Khalifa University http://www.kustar.ac.ae

[3] United Arab Emirates University http://www.uaeu.ac.ae

[4] American University of Beirut http://www.aub.edu.lb

[5] University of California, Los Angeles http://www.ucla.edu

[6] University of Washington, Seattle http://www.washington.edu

[7] ABET EAC, CAC Accreditation Board for Engineering and Technology.

http:/ / www.abet.org

[8] CAA, Commission for Academic Accreditation http://www.caa.ae

[9] CEA, Commission on English Language Program Accreditation http://www.cea-accredit.org

[10] "Improvement plans of College of Engineering University of Kufa", QA Committee, June 2013.

[11] "Rehabilitation of the Iraqi Higher Education System", Project Document, UNESCO, 2013.

[12] "Towards excellence in medical education and health care", Report on the Workshop on accreditation of medical education in Iraq, Amman, Jordan 31 March - 1 April 2016.

[13] "Towards self-assessment of 12 Colleges of Engineering in Iraq", Report, Doha (Qatar), June 6 -10, 2011.

[14] Curriculum Guidelines for UG Degree Programs in Computer Science, ACM, IEEE Computer Society, December 2013.

[15] Report in the Computing Curricula Series, Joint Task Force on Computer Engineering Curricula, ACM,IEEE, CE2016

[16] PROGRAM ASSESSMENT HANDBOOK, University of Central Florida, 2008 edition.

\section{APPENDIX}

\section{Glossary}

(Compiled From Various Sources)

(Different definitions/interpretations may be found depending on the source and/or contexts assumed)

Accreditation: a process of assessment \& review which enables a HE program or institution to be recognised or certified as meeting appropriate standards by a review of written information, self-studies, site visits to the educational program, and thoughtful consideration of 
the findings by a review committee.

Assessment: (program level) is one or more processes that identify, collect, and prepare data to evaluate the achievement of program outcomes and program educational objectives.

Capacity building: planned development of (or increase in) knowledge, output rate, management, skills, and other capabilities of an organization through acquisition, incentives, technology, and/or training.

CLO: a Course Learning Outcome is a statement of what the learner is expected to be able to do on successful completion of the course in order to demonstrate their knowledge, understanding, skills and/or competences

Curriculum: an educational plan that spells out which goals and objectives should be achieved, which topics should be covered and which methods are to be used for learning, teaching and evaluation. Deming Wheel: an iterative model developed by W. Edwards Deming composed of four functional elements: plan, do, study, and act. It is a looping model based on the principles of continuous process improvement.

e-learning. E-learning is a term applied to any form of learning which is electronically based. The requirements for a course delivered through e-learning are the same as those that apply to any credit-bearing course. Electronically delivered courses must have learning outcomes, a syllabus or outline of study, regular and systematic assessments, and an opportunity for students to interact with the faculty member teaching the course. The student-instructor and student-student interaction may be entirely electronically based, or it may include bringing students together physically from time to time. The latter is often referred to as a hybrid course or blended course in that it combines electronic learning with traditional classroom learning.

External reviews: are valuable assessment tools that can help shape the content and objectives of an academic program. In addition to satisfying a provision for accreditation, these reviews should be viewed as an opportunity to develop independent opinions about a department's program. They may be tailored to address specific programmatic concerns or assist in developing new initiatives that might benefit from a third-party evaluation.

Goals: Description of intended results of learning stated in global, general terms, e.g. clear communication, problem solving. A goal is a specific target, an end result or something to be desired.
Institutional effectiveness: The capacity of an institution to assess, verify, and enhance the fulfillment of its mission and purposes, giving primary focus to the attainment of its educational objectives for the purpose of continuous improvement of student learning, student development, and administrative unit operations.

KPIs : Key Performance Indicators are a set of statistical indicators designed with the purpose of offering an objective measure of how a HEI is performing.

Logframe: 'Logical Framework', describes both a general approach to project or program planning, monitoring and evaluation, and - in the form of a 'logframe matrix' - a discrete planning and monitoring tool for projects and programs. Logframe matrices are developed during project/program design and appraisal stages, and are subsequently updated throughout implementation while remaining an essential resource for ex-post evaluation.

OBE: Outcome Based Education, a method of curriculum design and teaching that focuses on what students gained and actually do after they are taught.

Peer review is the process of evaluating the provision, work process, or output of an individual or collective who operating in the same milieu as the reviewer(s).

Peer review: The evaluation of work by one or more people of similar competence to the producers of the work (peers). It constitutes a form of self-regulation by qualified members of a profession within the relevant field. Peer review methods are employed to maintain standards of quality, improve performance, and provide credibility.

PLO: A Program Learning Outcome is a statement of what the learner is expected to know, understand or be able to do on successful completion of the entire program.

PEO: Program Educational Objectives (ABET) are broad statements that describe what graduates are expected to attain within a few years of graduation. PEOs are based on the needs of the program's constituencies.

QA : Quality Assurance, comprises all those planned and systematic actions (policies, strategies, attitudes, procedures and activities) necessary to provide adequate demonstration that quality is being maintained and enhanced and the products and services meet the specified quality standards. In higher education, quality assurance is the totality of systems, resources and information devoted to maintaining and improving the quality and standards of teaching, scholarship and research as well as students' learning experience.

Stakeholder: Anyone with a vested interest in the outcome of a program (such as faculty, students, 
administration, community members, employers, alumni, and governing bodies).

SWOT: SWOT analysis (alternatively SWOT matrix) is an acronym for strengths, weaknesses, opportunities, and threats and is a structured planning method that evaluates those four elements of an organization, project or business venture. A SWOT analysis can be carried out for a company, product, place, industry, or person. It involves specifying the objective of the business venture or project and identifying the internal and external factors that are favorable and unfavorable to achieve that objective.

Vision: (in the strategic planning context) is a picture the organization in the medium to long term future. It is where the organization ultimately wants to end up in perhaps 5-10 years. Once the vision is formed, it enables the planners to develop goals \& objectives and thus set a direction for the organization. 